\title{
Autologous arteriovenous fistula is associated with superior outcomes in elderly hemodialysis patients
}

\author{
Eunjin Bae', Hajeong Lee ${ }^{2,3}$, Dong Ki Kim², ${ }^{2,3}$ Kook-Hwan Oh², Yon Su Kim², ${ }^{2,3}$ Curie Ahn, ${ }^{2,3}$ Jin Suk Han²,
} Sang-II Min ${ }^{4}$, Seung-Kee Min ${ }^{4}$, Hyo-Cheol Kim ${ }^{5}$ and Kwon Wook Joo $2,3,6^{*}$

\begin{abstract}
Background: The number of elderly patients with end-stage renal disease is increasing rapidly. The higher prevalence of comorbidities and shorter life expectancy in these patients make it difficult to decide on the type of vascular access (VA). We explored the optimal choice for VA in elderly hemodialysis patients.

Methods: We included elderly patients (> 65 years) visiting our VA clinic and divided them into three groups as follows: radiocephalic arteriovenous fistula (AVF), brachiocephalic AVF, and prosthetic arteriovenous graft (AVG). The primary outcomes were VA abandonment and all-cause mortality. The secondary outcome was maturation failure (MF).

Results: Of 529 patients, $61.2 \%$ were men. The mean age was $73.6 \pm 6.0$ years. The VA types were as follows: 49.9\% radiocephalic AVF, 31.8\% brachiocephalic AVF, and 18.3\% AVG. Patients with an AVG tended to be older, female, and have a lower body mass index. More than half of patients $(n=302,57.1 \%)$ started dialysis with central catheters, but the proportion of predialysis central catheter placement was not different among the VA types. Radiocephalic AVF was significantly superior to AVG in terms of VA abandonment $(P=0.005)$ and all-cause mortality $(P<0.001)$ in spite of a higher probability of MF. Brachiocephalic AVF was associated with a shorter time to the first needling and fewer interventions before maturation than radiocephalic AVF.
\end{abstract}

Conclusions: Autologous AVF was suggested as the preferred VA choice in terms of long-term outcomes in elderly patients.

Keywords: Elderly, Hemodialysis, Vascular access type, Vascular access abandonment, All-cause mortality

\section{Background}

The number of aging patients with end-stage renal disease (ESRD) is rapidly increasing. According to the United States Renal Data System report, the prevalence of ESRD increased from 4156 per million in 2000 to 6223 per million in 2015 in people aged $>65$ years [1]. Similarly, the proportion of elderly ESRD patients aged $>65$ years has increased over time, reaching 45.9\% in 2016 in Korea $[2,3]$. Dialysis initiation in elderly patients with a higher burden of age-related problems is associated with a

\footnotetext{
* Correspondence: junephro@gmail.com

$\mathrm{EB}$ and $\mathrm{HL}$ are contributed equally and co-first authors.

${ }^{2}$ Department of Internal Medicine, Seoul National University Hospital, Seoul, South Korea

${ }^{3}$ Kidney Reasearch Institute, Seoul National University College of Medicine,

Seoul, South Korea

Full list of author information is available at the end of the article
}

variety of concerns, including the selection of vascular access (VA).

The current Kidney Disease Outcomes Quality Initiative guidelines support the Fistula First Initiative for all HD patients. Autologous arteriovenous fistulas (AVFs) have been preferred VA for the past decade [4-6] because AVFs have the lowest risk of infectious complications, the longest patency, and superior survival rate despite difficulties with maturation. However, the optimal VA strategy in elderly dialysis patients remains unclear because of their relatively shorter life expectancy, higher prevalence of comorbidities, and difficulty in VA maturation. In recent years, some studies have presented different opinions on the Fistula First Initiative in elderly patients. Some studies have suggested that insertion of an AVG in the predialysis period could be beneficial in elderly patients by sparing transient catheter insertion and related

(C) The Author(s). 2018 Open Access This article is distributed under the terms of the Creative Commons Attribution 4.0 International License (http://creativecommons.org/licenses/by/4.0/), which permits unrestricted use, distribution, and 
complications [7-9]. Another study suggested a catheter as the main form of dialysis access in very elderly patients needing dialysis in terms of maturation failure (MF) [10]. However, there are concerns about catheter-related bloodstream infections and shorter survival. In elderly patients, few studies have compared the survival rates following AVF and AVG creation for VA. Some studies showed longer survival for AVFs [11-14], whereas other studies showed similar or shorter survival for AVFs compared with AVGs [15-17].

Most previous studies compared one outcome, such as MF, VA abandonment, or patient survival rate, between patients receiving an AVF or AVG rather than comparing the different VA subtypes. With this in mind, the aim of this study was to evaluate which VA type is better for each clinical outcome in elderly Koreans.

\section{Methods}

\section{Study population}

We retrospectively enrolled outpatients visiting Seoul National University Hospital Vascular Access Clinic between January 2008 and March 2014 [18].

Elderly patients aged $>65$ years who were maintained on HD were included. Patients who 1) had no VA, 2) visited our clinic only during an emergency, or 3 ) had undergone intervention or surgical treatment for VA within

Table 1 Patient characteristics by the vascular access type

\begin{tabular}{|c|c|c|c|c|c|}
\hline & $\begin{array}{l}\text { Total } \\
(N=529)\end{array}$ & $\begin{array}{l}\text { RC AVF } \\
(N=264)\end{array}$ & $\begin{array}{l}\text { BC AVF } \\
(N=168)\end{array}$ & $\begin{array}{l}\text { AVG } \\
(N=97)\end{array}$ & $P$ \\
\hline Age (years) & $73.6 \pm 6.0$ & $72.9 \pm 5.8$ & $74.2 \pm 6.0$ & $74.9 \pm 6.4$ & 0.007 \\
\hline Men (N, \%) & $324(61.2)$ & $176(66.7)$ & $92(54.8)$ & $56(57.7)$ & 0.087 \\
\hline BMI $\left(\mathrm{kg} / \mathrm{m}^{2}\right)$ & $23.1 \pm 3.3$ & $23.5 \pm 3.1$ & $22.8 \pm 3.5$ & $22.7 \pm 3.3$ & 0.043 \\
\hline $\mathrm{SBP}(\mathrm{mmHg})$ & $130.0 \pm 19.5$ & $131.0 \pm 18.6$ & $128.7 \pm 18.1$ & $129.2 \pm 24.0$ & 0.473 \\
\hline $\mathrm{DBP}(\mathrm{mmHg})$ & $69.3 \pm 10.8$ & $69.7 \pm 10.7$ & $68.4 \pm 10.3$ & $70.0 \pm 12.1$ & 0.466 \\
\hline Hemoglobin (g/dL) & $10.2 \pm 1.4$ & $10.1 \pm 1.4$ & $10.0 \pm 1.4$ & $10.5 \pm 1.4$ & 0.039 \\
\hline Albumin (g/dL) & $3.5 \pm 0.5$ & $3.5 \pm 0.5$ & $3.5 \pm 0.6$ & $3.4 \pm 0.4$ & 0.126 \\
\hline Total chol. (g/dL) & $153.4 \pm 39.2$ & $151.7 \pm 37.5$ & $153.7 \pm 38.8$ & $158.1 \pm 44.8$ & 0.428 \\
\hline Calcium (mg/dL) & $8.5 \pm 0.7$ & $8.5 \pm 0.7$ & $8.4 \pm 0.7$ & $8.6 \pm 0.7$ & 0.222 \\
\hline Phosphorus (mg/dL) & $4.2 \pm 1.1$ & $4.2 \pm 1.1$ & $4.1 \pm 1.0$ & $4.1 \pm 1.2$ & 0.614 \\
\hline Glucose (mg/dL) & $123.7 \pm 56.6$ & $126.1 \pm 57.4$ & $117.2 \pm 51.0$ & $128.7 \pm 62.8$ & 0.206 \\
\hline PTH (pg/mL) & $168.5 \pm 149.1$ & $170.8 \pm 149.5$ & $173.4 \pm 142.6$ & $147.0 \pm 169.6$ & 0.670 \\
\hline Uric Acid (mg/dL) & $6.7 \pm 2.1$ & $6.8 \pm 2.1$ & $6.6 \pm 2.4$ & $6.2 \pm 1.7$ & 0.031 \\
\hline hs-CRP (mg/dL) & $2.4 \pm 4.3$ & $2.1 \pm 3.8$ & $2.4 \pm 4.8$ & $3.1 \pm 4.6$ & 0.254 \\
\hline Follow up duration (month) & $67.1 \pm 44.6$ & $71.0 \pm 46.5$ & $66.0 \pm 41.3$ & $58.1 \pm 43.8$ & 0.048 \\
\hline Etiology of ESRD & & & & & 0.538 \\
\hline $\mathrm{DM}(\mathrm{N}, \%)$ & $247(45.7)$ & $126(47.7)$ & $74(44.0)$ & $42(43.3)$ & \\
\hline HTN (N, \%) & $40(7.6)$ & $20(7.6)$ & $13(7.7)$ & $7(7.2)$ & \\
\hline GN (N, \%) & $35(6.6)$ & $18(6.8)$ & $8(4.8)$ & $9(9.3)$ & \\
\hline Others (N, \%) & $61(11.3)$ & $22(8.3)$ & $24(14.3)$ & $14(14.4)$ & \\
\hline Unknown (N, \%) & $152(28.7)$ & $78(29.5)$ & $49(29.2)$ & $25(25.6)$ & \\
\hline \multicolumn{6}{|l|}{ Comorbidities } \\
\hline $\mathrm{DM}(\mathrm{N}, \%)$ & $304(57.5)$ & $157(59.5)$ & $93(55.4)$ & $54(55.7)$ & 0.648 \\
\hline HTN (N, \%) & $419(79.2)$ & $218(82.6)$ & $131(78.0)$ & $70(72.2)$ & 0.087 \\
\hline CAD (N, \%) & $120(22.7)$ & $60(22.7)$ & $32(19.0)$ & $28(28.9)$ & 0.184 \\
\hline PVD $(N, \%)$ & $26(4.9)$ & $9(3.4)$ & $11(6.5)$ & $6(6.2)$ & 0.276 \\
\hline CVD $(N, \%)$ & $106(20.0)$ & $53(20.1)$ & $27(16.1)$ & $26(26.8)$ & 0.110 \\
\hline CHF $(N, \%)$ & $77(14.6)$ & $32(12.1)$ & $31(18.5)$ & $14(14.4)$ & 0.191 \\
\hline Malignancy (N, \%) & $98(18.3)$ & $75(17.2)$ & $23(23.2)$ & $98(18.3)$ & 0.161 \\
\hline
\end{tabular}

Values are presented as number (\%) or mean \pm standard deviation

$A V F$ arteriovenous fistula, $A V G$ arteriovenous graft, $B M I$ body mass index, $B C$ brachiocephalic, $C A D$ coronary artery disease, $C V D$ cerebrovascular disease, $C H F$ congestive heart failure, DBP diastolic blood pressure, DM diabetes mellitus, ESRD end stage renal disease, GN glomerular nephritis, $h s-C R P$ high-sensitivity $C$ reactive protein, HTN hypertension, $P T H$ parathyroid hormone, $P V D$ peripheral vascular disease, SBP systolic blood pressure, $R C$ radiocephalic 
the last month were excluded. After exclusion, we stratified the remaining patients into three groups according to VA types, as follows: radiocephalic (RC) AVF, brachiocephalic (BC) AVF, and AVG.

\section{Clinical data collection}

We retrospectively reviewed the demographic and clinical data. Body mass index (BMI) was calculated as weight in $\mathrm{kg}$ divided by height in $\mathrm{m}^{2}$. Laboratory data and etiology of ESRDwere obtained at the time of VA creation. We gathered information from these pre-operative surveillance techniques. We also examined VA duplex ultra-sonography (DUS) findings at the time of the first visit. After surgery for VA creation, we regularly followed-up VA maturation status with a 2-4-week interval until the VA had matured sufficiently. We collected data on the time to the first VA use and whether patients received percutaneous transluminal angioplasty (PTA) due to poor maturation of the VA.

\section{Outcome assessment}

The primary endpoints were VA abandonment and allcause mortality. VA abandonment was defined as an access that could no longer be used for 1- or 2-needle dialysis as it might be unable to provide adequate flow and/or be deemed unsafe for the patient if the associated problem could not be corrected by medical, surgical, or radiological interventions or rest [18]. For patients who withdrew from the study, we ascertained the mortality data from both an electronic medical record review and Statistics Korea [19].

The secondary endpoint was MF. MF was defined as a VA that could not be used successfully for dialysis from 90 days following its creation, despite radiological or surgical intervention [20].

\section{Statistical analysis}

Differences among the three groups were analyzed using the chi-square test for categorical variables and the analysis of variance $t$-test for continuous variables. The data are presented as mean \pm standard deviation, median with range, or frequency (count and percentage). To explore the association between VA type and primary endpoints, a Kaplan-Meier curve was plotted according to VA types. Survival differences were compared using the log-rank test. To explore the association between VA types and Primary endpoints, multivariate Cox proportional hazards regression analysis using backward stepwise process was applied. Variables that showed a significant association $(P<0.10)$ in univariate analysis or were of considerable theoretical relevance were entered into the multivariate Cox proportional hazards regression models.

To assess the relationship between MF and VA types, we excluded patients who died within 90 days or follow up loss, and performed multivariate logistic regression analysis.

Statistical analyses were performed using SPSS version 21.0 for Windows (SPSS Inc., Chicago, IL, USA). Statistical significance was defined as a $P$-value $<0.05$.

\section{Results}

\section{Baseline patient characteristics}

A total of 529 patients were included in the final analysis. Among them, 432 (81.7\%) patients received an AVF, including 264 (61.1\%) RC and 168 (38.9\%) BC fistulas. AVGs were placed in $97(18.3 \%)$ patients. The mean age was $73.6 \pm 6.0$ years and $61.2 \%$ of patients were men. Table 1 compares the baseline characteristics of the three VA groups. Patients receiving an AVG were older and had a lower BMI than those who received an RC AVF but were similar to those who received a BC AVF. Furthermore, their hemoglobin levels were higher but serum uric acid (UA) levels were lower than those of patients with AVFs.

Table 2 Analysis of the clinical characteristics before first use of vascular access according to vascular access type

\begin{tabular}{|c|c|c|c|c|c|c|}
\hline & & $\begin{array}{l}\text { Total } \\
(N=529)\end{array}$ & $\begin{array}{l}\text { RC AVF } \\
(N=264)\end{array}$ & $\begin{array}{l}\text { BC AVF } \\
(N=168)\end{array}$ & $\begin{array}{l}\text { AVG } \\
(N=97)\end{array}$ & $P$ \\
\hline \multirow[t]{3}{*}{ CVC } & None & $227(42.9)$ & $121(45.8)$ & $69(41.1)$ & $37(38.1)$ & 0.358 \\
\hline & $\mathrm{IJC}$ & $3(0.6)$ & $2(0.8)$ & $0(0)$ & $1(1.0)$ & \\
\hline & Permanent catheter & $299(56.5)$ & $141(53.4)$ & $99(58.9)$ & $59(60.0)$ & \\
\hline CVC duration (days) & & $113.4 \pm 73.5$ & $115.3 \pm 68.7$ & $112.7 \pm 63.7$ & $109.3 \pm 101.4$ & 0.891 \\
\hline \multirow[t]{4}{*}{ Preoperative surveillance } & None & $192(36.4)$ & $123(46.8)$ & $53(31.5)$ & $16(16.5)$ & $<0.001$ \\
\hline & Duplex ultrasonography & $207(39.2)$ & $102(38.8)$ & $85(50.6)$ & $20(20.6)$ & \\
\hline & Venography & $60(11.4)$ & $17(6.5)$ & $19(13.3)$ & $24(24.7)$ & \\
\hline & Both & $69(13.1)$ & $21(8.0)$ & $11(6.5)$ & $37(38.1)$ & \\
\hline Time to 1st use (days) & & $64.0(14.0-124.0)$ & $75.0(12.0-138.0)$ & $65.5(8.8-122.3)$ & $35.0(5.0-65.0)$ & 0.001 \\
\hline PTA before maturation & & $112(21.2)$ & $70(26.5)$ & $27(16.1)$ & $15(15.5)$ & 0.011 \\
\hline
\end{tabular}

Values are presented as number (\%), mean \pm standard deviation, or median with range

AVF arteriovenous fistula, AVG arteriovenous graft, BA brachial artery, BC brachiocephalic, CVC central vein catheter, IJC internal jugular catheter, PSV peak systolic velocity, PTA percutaneous transluminal angioplasty, $R C$ radiocephalic 
Table 3 Analysis of the duplex ultrasonography findings before first use of vascular access

\begin{tabular}{|c|c|c|c|c|c|c|}
\hline & & $\begin{array}{l}\text { Total } \\
(N=529)\end{array}$ & $\begin{array}{l}\text { RC AVF } \\
(N=264)\end{array}$ & $\begin{array}{l}\text { BC AVF } \\
(N=168)\end{array}$ & $\begin{array}{l}\text { AVG } \\
(N=97)\end{array}$ & $P$ \\
\hline \multirow[t]{6}{*}{ Duplex ultrasonography } & BA diameter $(\mathrm{cm})$ & $5.7 \pm 3.7$ & $5.7 \pm 4.4$ & $5.7 \pm 3.5$ & $5.6 \pm 1.1$ & 0.955 \\
\hline & BA flow (ml/min) & $1009.6 \pm 610.3$ & $860.8 \pm 477.8$ & $1226.6 \pm 743.7$ & $1005.6 \pm 535.0$ & $<0.001$ \\
\hline & BA PVS (cm/sec) & $207.0 \pm 84.7$ & $188.1 \pm 68.1$ & $238.9 \pm 99.2$ & $195.0 \pm 76.8$ & $<0.001$ \\
\hline & Cephalic vein diameter & $5.7 \pm 6.1$ & $4.9 \pm 3.0$ & $6.6 \pm 6.7$ & $6.0 \pm 10.2$ & $<0.001$ \\
\hline & Cephalic vein flow & $911.8 \pm 664.8$ & $726.5 \pm 505.3$ & $1153.2 \pm 788.3$ & $1008.8 \pm 672.9$ & $<0.001$ \\
\hline & Cephalic vein PSV & $161.7 \pm 73.3$ & $146.3 \pm 64.6$ & $167.7 \pm 72.6$ & $194.2 \pm 85.2$ & 0.032 \\
\hline
\end{tabular}

Values are presented as number (\%), mean \pm standard deviation, or median with range

$A V F$ arteriovenous fistula, $A V G$ arteriovenous graft, $B A$ brachial artery, $B C$ brachiocephalic, $P S V$ peak systolic velocity, $R C$ radiocephalic

Otherwise, there were no significant differences according to VA types with respect to blood pressure, laboratory tests, etiology of ESRD, and co-morbidities.

\section{Preoperative VA-related characteristics}

More than half of patients $(n=302,57.1 \%)$ started their HD using a CVC. The mean duration of CVC use was $113.6 \pm 73.2$ days. Of these, 27 (9.0\%) had VA abandonment, 30 (9.9\%) died, 57 (22.4\%) could not use their VA due to MF, 94 (33\%) received PTA and 24 (8.4\%) received 2nd or revision operation. Before access creation, $337(63.7 \%)$ patients received preoperative surveillance for artery and vein status. Among them, 207 (61.4\%) patients were evaluated by DUS, 60 (17.8\%) by venography, and $69(20.5 \%)$ by both DUS and venography. A total of 112 (21.2\%) patients received PTA before maturation. The median time to the first use of the VA was 64.0 (14.0-124.0) days.

Table 2 compares the preoperative VA-related clinical characteristics according to VA types. There was no difference in CVC placement proportion and duration according to VA types. Patients who underwent AVG placement tended to receive more aggressive preoperative surveillance, although their maturation time was shorter and proportion of vascular intervention before maturation was lower than in patients who received AVFs. Patients with an RC AVF had the lowest proportion of preoperative vascular surveillance. However, their rate of PTA before maturation was highest and their time to needling was longest among all of the VA types assessed. The proportion of patients with a $\mathrm{BC}$ AVF receiving intervention before maturation was much lower than that of patients with an RC AVF but similar to that of patients with an AVG.

\section{DUS findings}

Table 3 compares the DUS findings at the time of the first use according to VA types. The diameter of the brachial artery (BA) was not different according to the type of VA. BA flow and peak systolic velocity (PSV) was highest in $\mathrm{BC}$ fistulas. In addition, needling-site cephalic venous flow was highest in BC AVFs. PSV of the cephalic vein was highest in AVGs.

\section{Outcomes according to VA types}

During a mean follow-up of $66.9 \pm 44.5$ months, VA abandonment occurred in $8.2 \%(n=43)$ and death by any cause occurred in $24.2 \%(n=128)$ of elderly dialysis patients. Table 4 presents the clinical outcomes according to VA types. Figure 1 shows the VA abandonment and all-cause mortality rates according to VA types obtained using the Kaplan-Meier method. The VA abandonment rate was highest in AVGs, followed by $\mathrm{RC}$ AVFs and BC AVFs $(P=0.005)$. In terms of all-cause mortality, patients with an AVG showed the worst results, followed by those with a BC AVF and RC AVF $(P<0.001)$.

Table 5 summarizes the results of multivariate Cox regression analysis for outcomes. In multivariate Cox regression analysis, AVGs significantly elevated the VA abandonment risk (adjusted HR 2.77, 95\% CI 1.226.27, $P=0.033)$ compared with RC AVFs. Additionally, hemoglobin level (HR 1.41, 95\% CI 1.11-1.81,

Table 4 Clinical outcomes of the elderly hemodialysis patients according to VA Types

\begin{tabular}{|c|c|c|c|c|c|}
\hline & $\begin{array}{l}\text { Total } \\
(N=302)\end{array}$ & $\begin{array}{l}\text { RC AVF } \\
(N=143)\end{array}$ & $\begin{array}{l}\text { BC AVF } \\
(N=99)\end{array}$ & $\begin{array}{l}\text { AVG } \\
(N=60)\end{array}$ & $P$ \\
\hline VA abandonment (n, \%) & $43(8.2)$ & $22(8.4)$ & $8(4.8)$ & $13(13.5)$ & 0.043 \\
\hline All-cause mortality (n, \%) & $44(8.3)$ & $17(6.4)$ & $11(6.5)$ & $16(16.5)$ & 0.005 \\
\hline Maturation failure (n, \%) & $136(33.0)$ & $84(40.0)$ & $43(31.6)$ & $9(13.6)$ & $<0.001$ \\
\hline PTA before maturation ( $n, \%)$ & $112(21.2)$ & $70(26.5)$ & $27(16.1)$ & $15(15.5)$ & 0.011 \\
\hline Secondary operation (n, \%) & $30(6.1)$ & $8(3.3)$ & $12(7.7)$ & $10(11.2)$ & 0.018 \\
\hline
\end{tabular}




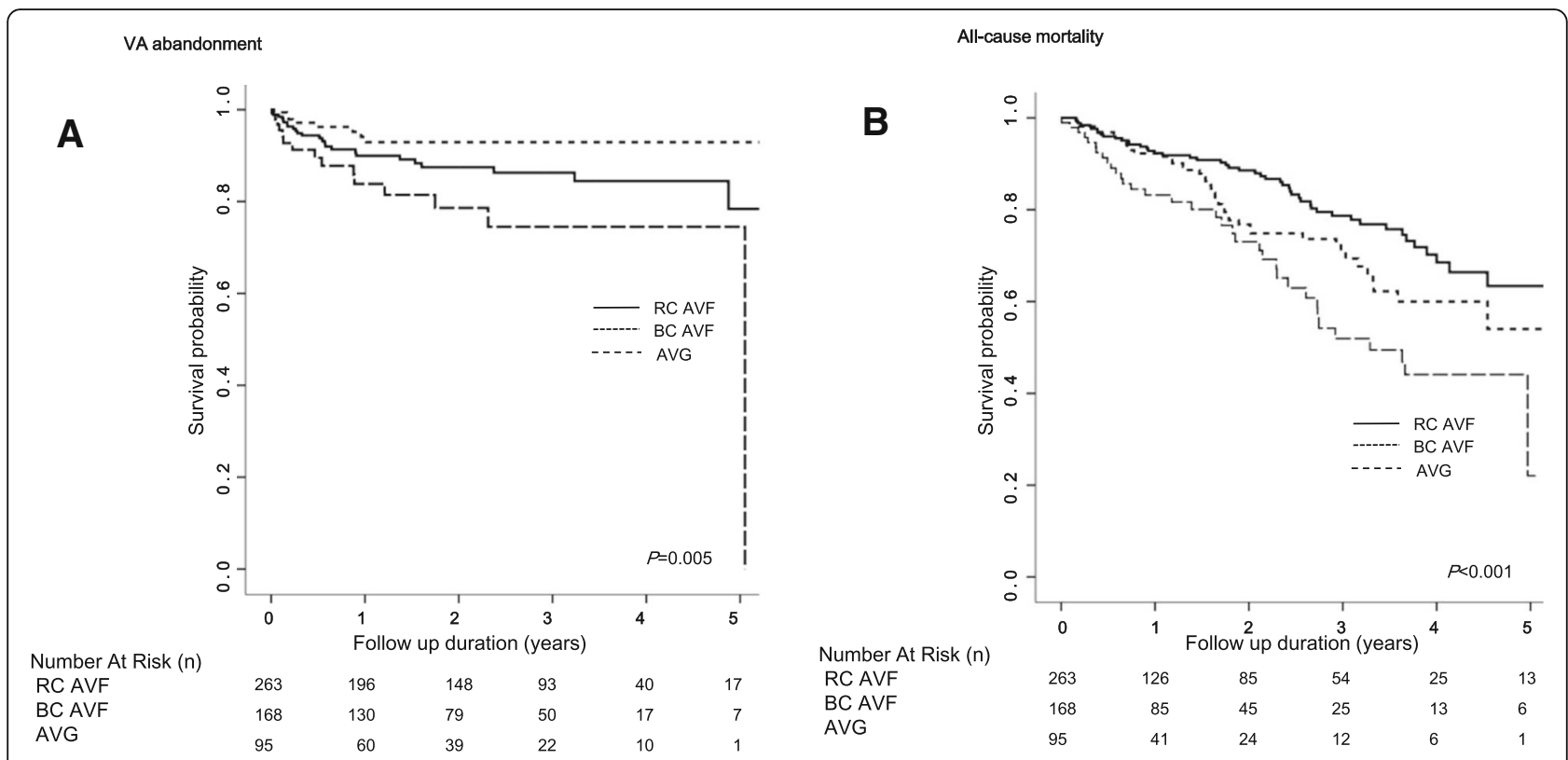

Fig. 1 Comparison of primary endpoints by vascular access type. Kaplan-Meier curve for vascular access abandonment (a), and all-cause mortality (b) according to vascular access type

$P=0.006)$ and BA diameter (HR 0.59, 95\% CI $0.37-$ $0.93, P=0.024$ ) were significantly associated with VA abandonment. In terms of all-cause mortality, AVGs were an independent risk factor for mortality (adjusted HR 2.65, 95\% CI 1.52-4.63, $P=0.003$ ). Age (adjusted HR 1.08 , 95\% CI 1.05-1.12, $P<0.001)$ and peripheral vascular disease (adjusted HR 2.39, 95\% CI 1.13-5.06, $P=0.023$ ) were significantly associated with all-cause mortality.

MF was observed in $33.0 \%(n=136)$ of patients. The rate was highest for RC AVFs ( $n=84,40.0 \%)$, followed by BC AVFs $(n=43,31.6 \%)$ and AVGs $(n=9,13.3 \%)$. When we explored the factors associated with MF, AVGs were associated with significantly lower risks of MF than
RC fistulas (adjusted odds ratio 0.24, 95\% CI 0.09-0.60, $P=0.002$ ). BC fistulas tended to have a lower MF risk than RC fistulas, although this difference was not statistically significant.

Outcomes according to VA types in very elderly patients We identified the outcomes associated with different VA types in very elderly patients ( $\geq 80$ years). Figure $2 \mathrm{~b}$ shows the VA abandonment rate in patients aged $>80$ years determined using the Kaplan Meier method. There was no statistically significant relationship and no inferiority of AVFs compared to AVGs. In addition, AVFs were significantly superior to AVGs in terms of all-cause mortality.

Table $\mathbf{5}$ Hazard ratios of primary endpoints in elderly patients

\begin{tabular}{|c|c|c|c|c|c|c|}
\hline & \multicolumn{2}{|c|}{ VA abandonment } & \multicolumn{2}{|c|}{ All-cause mortality } & \multicolumn{2}{|l|}{ Maturation failure } \\
\hline & $\mathrm{HR}(95 \% \mathrm{Cl})$ & $P$ value & $\mathrm{HR}(95 \% \mathrm{Cl})$ & $P$ value & OR $(95 \% \mathrm{Cl})$ & $P$ value \\
\hline Age & - & - & $1.08(1.05-1.12)$ & $<0.001$ & & \\
\hline Hemoglobin & $1.41(1.11-1.81)$ & 0.006 & - & - & & \\
\hline Albumin & - & - & - & - & $2.61(1.6 .0-4.25)$ & $<0.001$ \\
\hline VA type (ref. RC AVF) & & 0.033 & & 0.003 & & 0.010 \\
\hline$B C$ AVF & $0.97(0.35-2.68)$ & 0.955 & $1.54(0.92-2.57)$ & 0.102 & $0.81(0.47-1.42)$ & 0.464 \\
\hline AVG & $2.77(1.22-6.27)$ & 0.015 & $2.65(1.52-4.63)$ & 0.001 & $0.24(0.09-0.60)$ & 0.002 \\
\hline PVD & - & - & $2.39(1.13-5.06)$ & 0.023 & & \\
\hline BA diameter & $0.59(0.37-0.93)$ & 0.024 & - & - & & \\
\hline
\end{tabular}

Adjusted for age, sex, BMI, systolic pressure, Hemoglobin, cholesterol, albumin, calcium, phosphorus, DM, CAD, PVD, CVD, CHF, VA type, history of CVC, duplex U/S findings (Brachial a. diameter, Brachial a. flow, Needling site diameter, Needling site flow)

$V A$ vascular access, $B M I$ body mass index, $C H F$ congestive heart failure, $B A$ brachial artery, SBP systolic blood pressure, $P V D$ peripheral vascular disease, $H R$ hazard ratio, $\mathrm{Cl}$ confidence index, $\mathrm{OR}$ odds ratio 


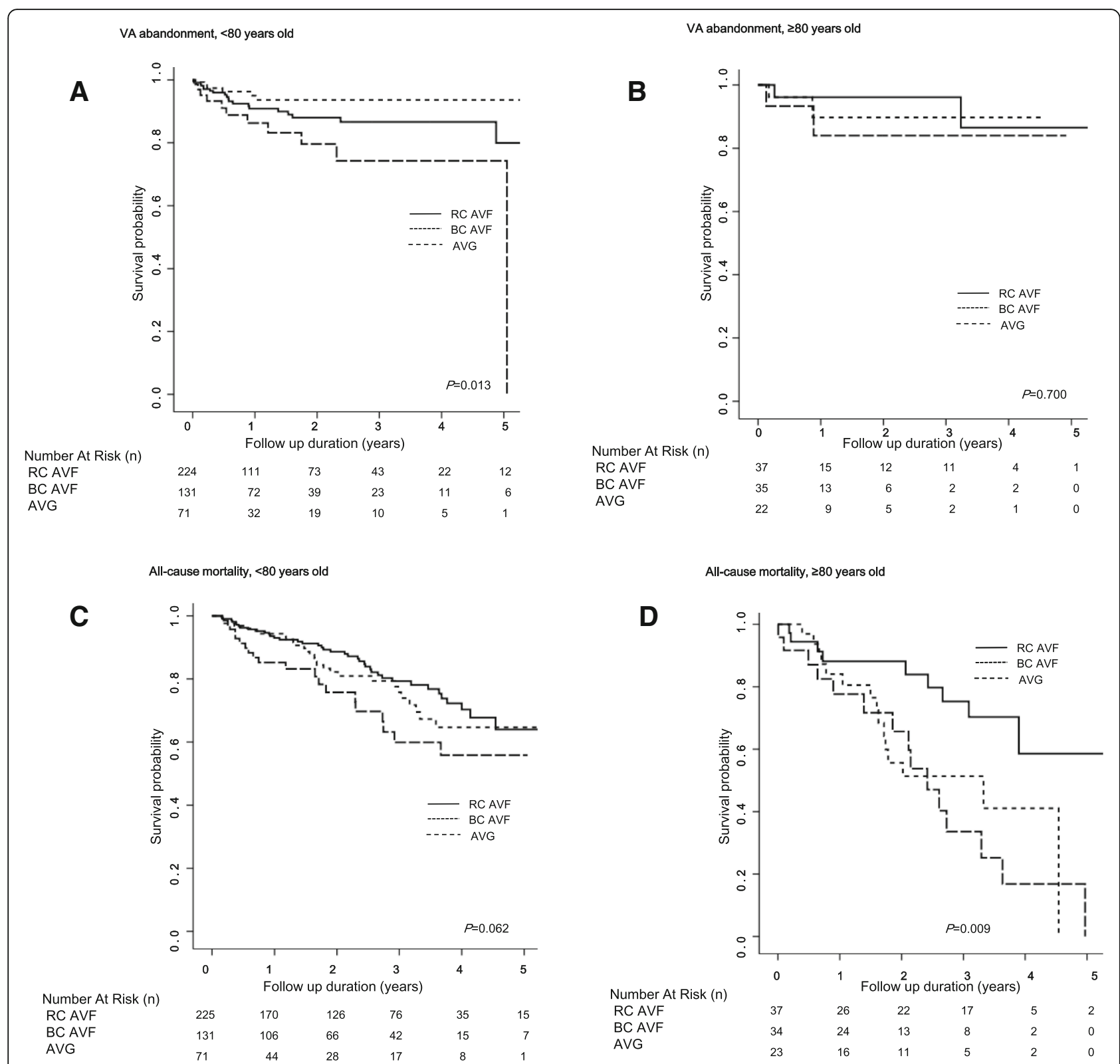

Fig. 2 Comparison of primary endpoints according to vascular access type in very elderly patients. Kaplan-Meier curve for vascular access abandonment in age $<80$ years old (a), $\geq 80$ years old $(\mathbf{b})$ and all-cause mortality in age $<80$ years old $(\mathbf{c}), \geq 80$ years old $(\mathbf{d})$ according to vascular access type

Table 6 shows the effect of VA type on outcomes in patients aged $>80$ years. In very elderly patients, RC AVFs were associated with lower risks of all-cause mortality than BC AVFs and AVGs. VA types did not have a significant effect on other outcomes, such as VA abandonment and MF.

\section{Discussion}

In this study, we investigated baseline characteristics, DUS findings, and outcomes according VA types in elderly HD patients. Our aim was to determine the optimal VA type in elderly patients. We found that AVFs were superior to AVGs with respect to all-cause mortality and VA abandonment, although AVFs were associated with a higher risk of MF in elderly HD patients. Among AVFs, BC fistulas showed similar benefits to RC fistulas in terms of VA abandonment, all-cause mortality, and MF risk. However, BC fistulas had a lower intervention rate than RC fistulas. Moreover, DUS findings were more favorable for $\mathrm{BC}$ fistulas than $\mathrm{RC}$ fistulas. Consequently, $\mathrm{BC}$ fistulas might be a VA type that is not inferior to RC fistulas for elderly dialysis patients. 
Table 6 Hazard ratios of vascular access type on endpoints according to age

\begin{tabular}{|c|c|c|c|c|c|c|}
\hline & \multicolumn{2}{|l|}{ VA abandonment } & \multicolumn{2}{|l|}{ All-cause mortality } & \multicolumn{2}{|l|}{ Maturation failure } \\
\hline & $\mathrm{HR}(95 \% \mathrm{Cl})$ & $P$ value & $\mathrm{HR}(95 \% \mathrm{Cl})$ & $P$ value & OR $(95 \% \mathrm{Cl})$ & $P$ value \\
\hline \multicolumn{7}{|l|}{ Age $<80$ years } \\
\hline VA type (ref. RC AVF) & & 0.019 & & & & 0.015 \\
\hline $\mathrm{BC}$ AVF & $0.55(0.18-1.70)$ & 0.299 & & & $0.68(0.39-1.20)$ & 0.184 \\
\hline AVG & $2.71(1.09-6.73)$ & 0.032 & & & $0.23(0.09-0.65)$ & 0.005 \\
\hline \multicolumn{7}{|l|}{ Age $\geq 80$ years } \\
\hline VA type (ref. RC AVF) & & & & 0.002 & & \\
\hline $\mathrm{BC}$ AVF & & & $3.47(1.34-9.01)$ & 0.011 & & \\
\hline AVG & & & $6.30(2.29-17.35)$ & $<0.001$ & & \\
\hline
\end{tabular}

Adjusted for age, sex, BMI, systolic blood pressure, Hemoglobin, cholesterol, albumin, calcium, phosphorus, DM, CAD, PVD, CVD, CHF, VA type, history of CVC, duplex U/S findings (BA diameter, BA flow, Cephalic vein diameter, Cephalic vein flow)

$A V F$ arteriovenous fistula, $A V G$ arteriovenous graft, $B A$ brachial artery, $B M I$ body mass index, $B C$ brachiocephalic, $C A D$ coronary artery disease, $C V C$ central vein catheter, CVD cerebrovascular disease, CHF congestive heart failure, DM diabetes mellitus, PVD peripheral vascular disease, PSV peak systolic velocity, PTA percutaneous transluminal angioplasty, $R C$ radiocephalic, U/S ultrasonography, $H R$ hazard ratio, $C l$ confidence index, $O R$ odds ratio

Inadequate VA leads to recurrent PTA, re-operation, and CVC insertion, which increase the risk of infection and mortality. In addition, inadequate VA is related to poor quality of life. Researchers have investigated various aspects of VA, such as timing, placement, and type. Some previous studies compared RC and BC AVFs. In terms of patency, BC AVFs have advantages over RC AVFs [7, 13, 21-23], whereas BC AVFs are associated with more steal syndrome than RC AVFs [24]. The present study demonstrated that AVFs are superior to AVGs in terms of all-cause mortality and VA abandonment but not MF. In patients aged 65-80 years, BC AVFs showed no significant difference in all-cause mortality compared to RC AVFs and favorable outcomes in terms of VA abandonment and MF. In patients aged $>80$ years, BC AVFs showed inferior outcomes to RC AVFs in terms of all-cause mortality. BC AVFs were associated with less PTA before maturation and better DUS findings than RC AVFs. In view of these findings, AVFs should be considered as the first-choice VA rather than AVGs in elderly patients. Furthermore, it is not necessary to insist on RC AVFs. Rather, the choice between BC and RC AVFs should be determined based on blood vessel status.

In this study, RC AVFs accounted for the largest proportion of AVFs at $61.1 \%$ in elderly patients, showing a large proportion of RC AVFs were placed compared to other studies. Other previous studies showed that $24.7 \%$ to $60.7 \%$ patients received RC AVFs in AVFs [13, 21-23]. It might be following reasons; skilled surgical technique, recently enrolled patients could have better vascular condition than the patients in the previous studies. There were no significant differences in gender or age between our study and previous studies.

The results of this study should be interpreted with caution. Although all patients were elderly, patients with RC AVFs had better vascular status and fewer co- morbidities than patients with other BC AVFs or AVGs. In this study, patients in the RC AVF group were the youngest and their BMI and UA level were higher than those of patients in the other VA type groups. The higher BMI and UA level could reflect the good nutritional status of patients in the RC AVF group in this study. Although, we adjusted for nutritional status and co-morbidities, the relationship between all-cause mortality and RC AVF should be interpreted as a surrogate marker rather than as an effect of RC AVF itself.

The present study investigated details related to VA in elderly dialysis patients, such as methods of VA surveillance before the first dialysis, DUS findings, interventions, first dialysis methods, MF, and VA abandonment. Previous studies mainly focused on outcome-related factors, whereas this study evaluated the overall characteristics associated with VA, such as the process of creating a VA and outcomes during the follow-up period.

We analyzed DUS findings, which were associated with the clinical outcomes of VA creation. Among the DUS findings, only BA diameter was significantly associated with VA abandonment. One previous study [25] showed that BA diameter was positively correlated with AVF success. Other studies $[26,27]$ reported good BA flow rate consequent to $\mathrm{RC}$ wrist AVF maturation. As such, the BA represents an ideal site for studying distal AVFs. As yet, there is no definite DUS finding that can predict VA outcomes. However, the results of this study could represent evidence that the BA is relatively important in DUS findings, especially in elderly patients.

The present study had some limitations. First, the study was retrospective in nature. As such, it was difficult to infer causal relationships and selection bias cannot be completely ruled out. Second, since most of the study population was Asian, the data cannot be generalized to other races. Third, DUS was performed by well-trained 
specialists but not by the same person, which could have led to differences in the DUS results. To overcome these limitations, well-planned prospective, multicenter studies are needed.

\section{Conclusions}

In conclusion, the fistula first strategy could also be applied to elderly HD patients with respect to VA abandonment and all-cause mortality. BC AVFs could be considered as the first-choice VA depending on the patient's condition.

\begin{abstract}
Abbreviations
AVF: Autologous arteriovenous fistula; AVG: Arteriovenous graft; BA: Brachial artery; BC: Brachiocephalic; BMI: Body mass index; Cl: Confidence interval; CVC: Central venous catheter; DUS: Duplex ultra-sonography; ESRD: Endstage renal disease; HD: Hemodialysis; HR: hazard ratio; PSV: Peak systolic velocity; PTA: Percutaneous transluminal angioplasty; RC: Radiocephalic; VA: Vascular access
\end{abstract}

\section{Acknowledgements}

Not applicable

\section{Funding}

No funding exits regarding this manuscript.

\section{Availability of data and materials}

The datasets used and analysed during the current study are available from the corresponding author on reasonable request.

\section{Authors' contributions}

Research idea and study design: $\mathrm{EB}, \mathrm{HL}, \mathrm{KO}, \mathrm{KWJ}$; acquisition of data: $\mathrm{EB}, \mathrm{HL}$, KO, YSK, JSH, SiM, SkM, HK; data analysis/interpretation: EB, HL, SiM, SkM, CA; statistical analysis: $E B, H L$, DKK, JSH; writing the manuscript: $E B, H L, Y S K, H K$, KWJ; review, revision, and final approval: all authors. All the authors read and approved the final version of the manuscript to be published.

\section{Ethics approval and consent to participate}

This study was reviewed and approved by the Institutional Review Board of Seoul National University Hospital. The requirement for patient informed consent was waived because of the retrospective design of the study. All clinical investigations were conducted based on the guidelines of the 2008 Declaration of Helsinki.

\section{Consent for publication}

Not applicable.

\section{Competing interests}

The authors declare that they have no competing interests.

\section{Publisher's Note}

Springer Nature remains neutral with regard to jurisdictional claims in published maps and institutional affiliations.

\footnotetext{
Author details

'Department of Internal Medicine, Gyeongsang National University Changwon Hospital, Changwon, South Korea. ${ }^{2}$ Department of Internal Medicine, Seoul National University Hospital, Seoul, South Korea. ${ }^{3}$ Kidney Reasearch Institute, Seoul National University College of Medicine, Seoul, South Korea. ${ }^{4}$ Department of Surgery, Seoul National University College of Medicine, Seoul, South Korea. ${ }^{5}$ Department of Radiology, Seoul National University College of Medicine, Seoul, South Korea. ${ }^{6}$ Department of Internal Medicine, Seoul National University College of Medicine, 101 Daehak-Ro, Jongno-Gu, Seoul 03080, Republic of Korea.
}

Received: 27 August 2018 Accepted: 19 October 2018

Published online: 06 November 2018

\section{References}

1. (USRDS) USRDS: Usrds 2016 annual data report: Atlas of chronic kidney disease and end-stage renal disease in the united states, 2016,

2. Jin DC, Yun SR, Lee SW, Han SW, Kim W, Park J, Kim YK. Current characteristics of dialysis therapy in Korea: 2016 registry data focusing on diabetic patients. Kidney Res Clin Pract. 2018:37:20-9.

3. Committee ER: Current renal replacement therapy in Korea 2016., 2016,

4. Lok CE, Foley R. Vascular access morbidity and mortality: trends of the last decade. Clin J Am Soc Nephrol. 2013;8:1213-9.

5. Dhingra RK, Young EW, Hulbert-Shearon TE, Leavey SF, Port FK. Type of vascular access and mortality in U.S. hemodialysis patients. Kidney Int. 2001;60:1443-51.

6. Daugirdas JT, Depner TA, Inrig J, Mehrotra R, Rocco MV, Suri RS, Weiner DE, Greer N, Ishani A, MacDonald R, Olson C, Rutks I, Slinin Y, Wilt TJ, Rocco M, Kramer H, Choi MJ, Samaniego-Picota M, Scheel PJ, Willis K, Joseph J, Brereton L. Kdoqi clinical practice guideline for hemodialysis adequacy: 2015 update. Am J Kidney Dis. 2015;66:884-930.

7. DeSilva RN, Patibandla BK, Vin Y, Narra A, Chawla V, Brown RS, GoldfarbRumyantzev AS. Fistula first is not always the best strategy for the elderly. J Am Soc Nephrol. 2013;24:1297-304.

8. Lee T, Thamer M, Zhang Y, Zhang Q, Allon M. Outcomes of elderly patients after predialysis vascular access creation. J Am Soc Nephrol. 2015;26:3133-40.

9. Leake AE, Yuo TH, Wu T, Fish L, Dillavou ED, Chaer RA, Leers SA, Makaroun MS. Arteriovenous grafts are associated with earlier catheter removal and fewer catheter days in the United States renal data system population. J Vasc Surg. 2015;62:123-7.

10. Diandra JC, Lo ZJ, Ang WW, Feng JF, Narayanan S, Tan GWL, Chandrasekar S. A review of arteriovenous fistulae creation in octogenarians. Ann Vasc Surg. 2018:46:331-6.

11. Xue JL, Dahl D, Ebben JP, Collins AJ. The association of initial hemodialysis access type with mortality outcomes in elderly medicare esrd patients. Am J Kidney Dis. 2003;42:1013-9.

12. Woo K, Goldman DP, Romley JA. Early failure of dialysis access among the elderly in the era of fistula first. Clin J Am Soc Nephrol. 2015;10:1791-8.

13. Lok CE, Oliver MJ, Su J, Bhola C, Hannigan N, Jassal SV. Arteriovenous fistula outcomes in the era of the elderly dialysis population. Kidney Int. 2005;67: 2462-9.

14. Lee T, Thamer M, Zhang Q, Zhang Y, Allon M. Vascular access type and clinical outcomes among elderly patients on hemodialysis. Clin J Am Soc Nephrol. 2017;12:1823-30

15. Drew DA, Lok CE, Cohen JT, Wagner M, Tangri N, Weiner DE. Vascular access choice in incident hemodialysis patients: a decision analysis. J Am Soc Nephrol. 2015;26:183-91.

16. Yuo TH, Chaer RA, Dillavou ED, Leers SA, Makaroun MS. Patients started on hemodialysis with tunneled dialysis catheter have similar survival after arteriovenous fistula and arteriovenous graft creation. J Vasc Surg. 2015;62: 1590-7 e1592.

17. Park HS, Kim WJ, Kim YK, Kim HW, Choi BS, Park CW, Kim YO, Yang CW, Kim YL, Kim YS, Kang SW, Kim NH, Jin DC. Comparison of outcomes with arteriovenous fistula and arteriovenous graft for vascular access in hemodialysis: a prospective cohort study. Am J Nephrol. 2016:43:120-8.

18. Kim HJ, Lee H, Kim DK, Oh KH, Kim YS, Ahn C, Han JS, Min SK, Min Sl, Kim $\mathrm{HC}$, Joo KW. Recurrent vascular access dysfunction as a novel marker of cardiovascular outcome and mortality in hemodialysis patients. Am J Nephrol. 2016;44:71-80.

19. Korean statistical information service, 2014. Available at: www.kosis.kr/. Accessed 30 Dec 2014.

20. Lee T, Mokrzycki M, Moist L, Maya I, Vazquez M, Lok CE. Standardized definitions for hemodialysis vascular access. Semin Dial. 2011;24:515-24.

21. Olsha O, Hijazi J, Goldin I, Shemesh D. Vascular access in hemodialysis patients older than 80 years. J Vasc Surg. 2015;61:177-83.

22. Renaud CJ, Pei JH, Lee EJ, Robless PA, Vathsala A. Comparative outcomes of primary autogenous fistulas in elderly, multiethnic asian hemodialysis patients. J Vasc Surg. 2012;56:433-9.

23. Staramos DN, Lazarides MK, Tzilalis VD, Ekonomou CS, Simopoulos CE, Dayantas JN. Patency of autologous and prosthetic arteriovenous fistulas in elderly patients. Eur J Surg. 2000;166:777-81. 
24. Goh MA, Ali JM, lype S, Pettigrew GJ. Outcomes of primary arteriovenous fistulas in patients older than 70 years. J Vasc Surg. 2016;63:1333-40.

25. Gibyeli Genek D, Tuncer Altay C, Unek T, Sifil A, Secil M, Camsari T. Can primary failure of arteriovenous fistulas be anticipated? Hemodial Int. 2015;19:296-305.

26. Lomonte C, Casucci F, Antonelli M, Giammaria B, Losurdo N, Marchio G, Basile $\mathrm{C}$. Is there a place for duplex screening of the brachial artery in the maturation of arteriovenous fistulas? Semin Dial. 2005;18:243-6.

27. Wiese P, Nonnast-Daniel B. Colour doppler ultrasound in dialysis access. Nephrol Dial Transplant. 2004;19:1956-63.

Ready to submit your research? Choose BMC and benefit from:

- fast, convenient online submission

- thorough peer review by experienced researchers in your field

- rapid publication on acceptance

- support for research data, including large and complex data types

- gold Open Access which fosters wider collaboration and increased citations

- maximum visibility for your research: over $100 \mathrm{M}$ website views per year

At $\mathrm{BMC}$, research is always in progress.

Learn more biomedcentral.com/submissions 